\title{
[Théodore de Bèze] Satyres chrestiennes de la cuisine papale
}

\section{Dario Cecchetti}

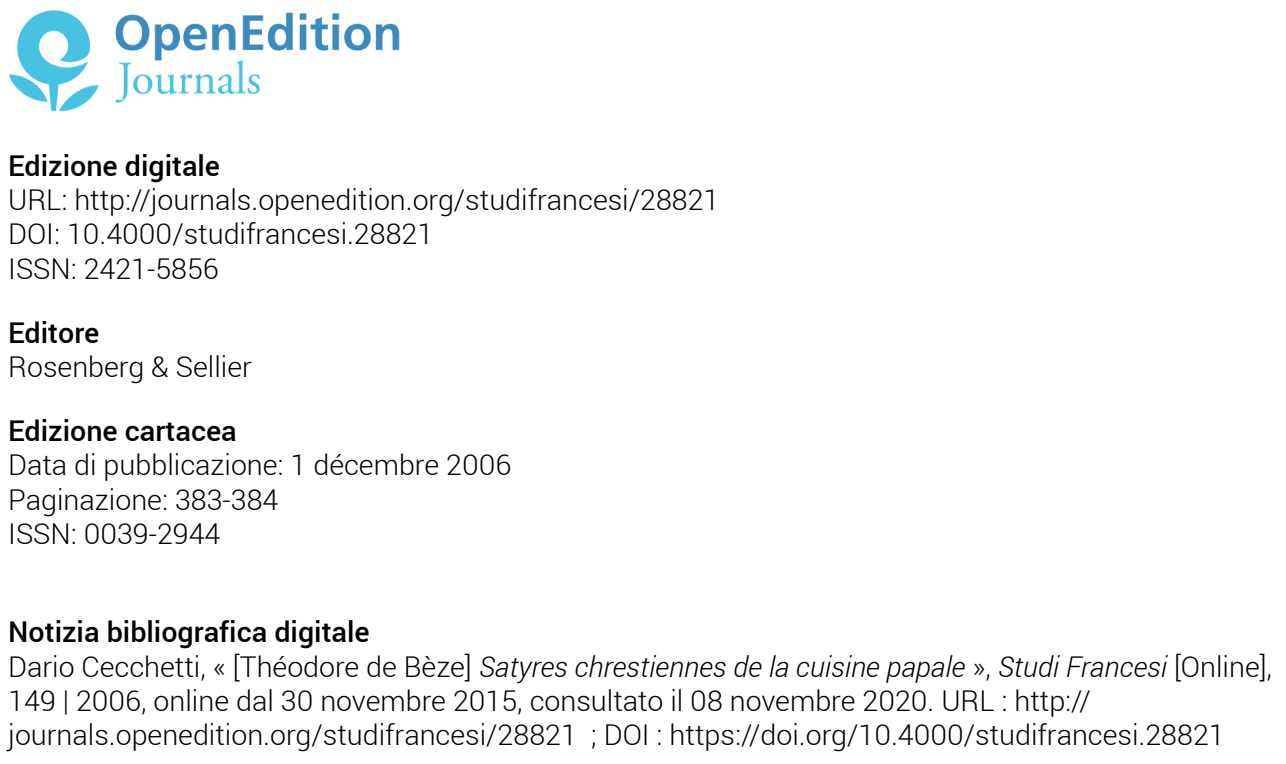

Questo documento è stato generato automaticamente il 8 novembre 2020.

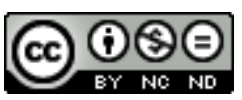

Studi Francesi è distribuita con Licenza Creative Commons Attribuzione - Non commerciale - Non opere derivate 4.0 Internazionale. 


\title{
[Théodore de Bèze] Satyres chrestiennes de la cuisine papale
}

\author{
Dario Cecchetti
}

\section{NOTIZIA}

[THÉODORE DE BÈZE] Satyres chrestiennes de la cuisine papale, édition critique par CHARLESANTOINE CHAMAY, Genève, Droz («Textes Littéraires Français», 576), 2005, pp. XCII-222.

1 Le otto composizioni in ottosillabi a rima baciata, dal titolo teologico-culinario, sono state pubblicate a Ginevra nel 1560, senza nome d'autore, per i tipi di Conrad Badius, figlio di Josse Badius e cognato di Robert Estienne. Attribuite di volta in volta a Conrad Badius stesso, a Pierre Viret, a Henri Estienne, a Joachim de Cognac, vengono rivendicate da Ch.-A. Chamay a Théodore de Bèze (cui già le attribuiva, perlomeno come lavoro in collaborazione, Yves Giraud) con una disamina convincente. L'opera satirica è interessante non solo per la ricostruzione delle polemiche religiose del tempo, ma anche come testimonianza linguistica di prim'ordine, soprattutto per l'originalità di una lingua satirica, fortemente immaginifica, che può richiamare Rabelais. La densa introduzione studia la tradizione polemica e il contesto storico in cui si situano le Satyres, ne analizza la struttura, ne fissa, come si è detto, l'attribuzione. L'annotazione al testo è minuziosa. Il ricco glossario è un buon strumento di ricerca linguistica. 